\title{
Thermodynamics of the S-Sn system: Implication for synthesis of earth abundant photovoltaic absorber materials
}

\author{
Greta Lindwall, ${ }^{* \dagger}$ ShunLi Shang, ${ }^{\dagger}$ Neal R. Kelly, ${ }^{\dagger}$ Tim Anderson, ${ }^{\dagger}$ and Zi-Kui Liu ${ }^{\dagger}$ \\ ${ }^{\dagger}$ Department of Materials Science and Engineering, The Pennsylvania State University, University Park, \\ Pennsylvania 16802, United States \\ ${ }^{ \pm}$Department of Chemical Engineering, University of Florida, Gainesville, Florida 32611, United States
}

Note: Supporting Information (SI) included.

\begin{abstract}
Development of earth-abundant, non-toxic, and environmentally friendly thinfilm photovoltaic (PV) absorber materials motivates the present thermodynamic study of the SSn system, which is modeled using the CALPHAD (CALculation of PHase Diagram) technique aided by first-principles calculations. The temperature-composition $(T-x)$, pressure-composition $(P-x)$ and pressure-temperature $(P-T)$ phase diagrams obtained from the modeling identifies stability regions for different tin sulfides. This provides quantitative information regarding growth windows and annealing conditions for intelligent discovery and design of synthesis routes to produce low-cost, high-efficiency thin film PV absorber materials such as $\mathrm{SnS}, \mathrm{SnS}_{2}$, $\mathrm{Sn}_{2} \mathrm{~S}_{3}$, and $\mathrm{Cu}_{2} \mathrm{ZnSn}(\mathrm{S}, \mathrm{Se})_{4}$.
\end{abstract}

Keywords: SnS; CZTS; phase diagrams; first-principles calculations 


\section{INTRODUCTION}

Increasing demand for sustainable energy has motivated research aimed to develop thin-film photovoltaic (PV) absorber materials containing earth abundant, non-toxic, and cost-effective raw materials (Kodigala, 2014). PV absorber materials that show promise include tin (Sn) chalcogenides such as the kesterites $\mathrm{Cu}_{2} \mathrm{ZnSnS}_{4}$ (CZTS) or $\mathrm{Cu}_{2} \mathrm{ZnSn}(\mathrm{S}, \mathrm{Se})_{4}(\mathrm{CZTSSe})$ and tin sulfides such as the orthorhombic $\mathrm{SnS}$, all of which possess suitable band gap energy with high absorption coefficient (Buchenau et al., 1971; Kodigala, 2014; Noguchi et al., 1994; Ogah et al., 2009; Sajeesh et al., 2010). Currently, the highest energy conversion efficiencies are $12.6 \%$ for CZTSSe(Wang et al., 2014) and $4.4 \%$ for SnS (Sinsermsuksakul et al., 2014; Steinmann et al., 2014), which are considerably lower than the theoretical Shockley-Queisser limit (Kodigala, 2014; Shockley and Queisser, 1961). It is expected that an efficiency of at least $15 \%$ is required for these earth abundant PV materials to be competitive with commercial $\mathrm{Cu}(\mathrm{In}, \mathrm{Ga}) \mathrm{Se}_{2}$ and CdTe solar cells with champion efficiencies of $20.5 \%$ and $19.6 \%$, respectively (Green et al., 2014). Consequently, researchers within the field are facing a great challenge to develop new and more advanced technical solutions regarding the syntheses of SnS and CZTS-based PV devices.

Examination of different routes used for production of CZTS-based devices indicates that the solar cells showing high efficiency have been fabricated by pathways that include reaction of metal or metal sulfide precursor in a sulfur (S) atmosphere (Ahmed et al., 2012; Katagiri et al., 2008; Shin et al., 2013) or by double-stage physical vapor deposition (Romero et al., 2011; Schubert et al., 2011), both of which involve an annealing treatment at elevated temperature, typically around $823 \mathrm{~K}$. The annealing seems to be necessary to homogenize the structure. Prevention of CZTS decomposition at this high temperature is critical for successful absorber 
synthesis (Redinger et al., 2011a, 2011b; Scragg et al., 2011). This requires specification of the process variables including the temperature, sulfur and $\mathrm{SnS}$ partial pressures, total chamber pressure as well as the overall metal composition. Defining these conditions empirically in this four-component system is challenging and hence, an understanding of equilibrium phase relations to predict the stability window for CZTS would assist greatly the search for optimal processing conditions.

A detailed knowledge of the phase relations also in the S-Sn phase diagram would be useful to provide guidance on the preparation of CZTS thin films. Under conditions for which the CZTS phase is not stable, it decomposes into its binary sulfides (Scragg et al., 2011) $\mathrm{Cu}_{2} \mathrm{~S}, \mathrm{ZnS}$, and SnS. Of these, SnS has the highest vapor pressure. Experimental observations suggest that $\mathrm{SnS}$ first forms as a solid phase on the CZTS film surface and then sublimes during the annealing step (Scragg et al., 2011). Ideally, the decomposition should be prevented or reversed by maintaining an ambient gas at higher tin and sulfur chemical potentials than their equilibrium values (Redinger et al., 2011a, 2011b).

Furthermore, the binary compound $\mathrm{SnS}$ has attracted interest in its own right as a relatively unexplored earth-abundant and non-toxic PV material (Biacchi et al., 2013). Important to PV applications, this compound shows p-type behavior, reportedly due to tin vacancies, and high absorption coefficient above the direct absorption edge at 1.3-1.5 eV (Buchenau et al., 1971; Noguchi et al., 1994; Ogah et al., 2009; Sajeesh et al., 2010). Furthermore, given its simpler chemistry than the multicomponent CZTS, the processing should be more straightforward. 
SnS crystallizes in an orthorhombic unit cell composed of double SnS layers perpendicular to the $b$ axis with tin and sulfur atoms covalently bonded within the layers and the layers bonded by the weak van der Waals bonds (Albers et al., 1961). These double layers are expected to give rise to a chemically inert surface with few surface states (Avellaneda et al., 2007) making it defecttolerant. It is suggested that this might reduce the carrier recombination loss due to defects at $\mathrm{p}-\mathrm{n}$ junctions or at grain boundaries, and hence, prolong the carrier lifetime (Sinsermsuksakul et al., 2011). Although limited experimental effort has been devoted to SnS PV device fabrication, 4.4 $\%$ devices have been demonstrated (Sinsermsuksakul et al., 2014). Various techniques for depositing SnS have been reported including thermal evaporation (Hartman et al., 2011; Johnson et al., 1999; Koteeswara Reddy et al., 2007; Miles et al., 2009; Nebesny et al., 1991; Steinmann et al., 2014; Wang et al., 2012), spray pyrolysis (Calixto-Rodriguez et al., 2009; Khadraoui et al., 2010; Sajeesh et al., 2010), sputtering from $\mathrm{SnS}$ and $\mathrm{SnS}_{2}$ targets (Banai et al., 2015, 2013) and metalorganic chemical vapor deposition (Bade et al., 2008; Barone et al., 2002, 2001; Hibbert et al., 2001; Price et al., 1999; Sinsermsuksakul et al., 2014). In each of these processes, understanding the thermodynamics of the S-Sn system is important to identify appropriate growth regions and annealing conditions to avoid formation of other binary compounds (i.e., $\mathrm{SnS}_{2}$ and $\mathrm{Sn}_{2} \mathrm{~S}_{3}$ ) (Banai et al., 2015; Barone et al., 2001; Mathews et al., 2010; Miles et al., 2009; Price et al., 1999; Sinsermsuksakul et al., 2014), and to increase the understanding of the point defect chemistry and hence defining process conditions that lead to suitable electrical properties.

It is noted that $\mathrm{Sn}_{2} \mathrm{~S}_{3}$ and $\mathrm{SnS}_{2}$ are also useful materials. $\mathrm{Sn}_{2} \mathrm{~S}_{3}$ exhibits a band gap of $0.95 \mathrm{eV}$ (Sánchez-Juárez et al., 2005) and has been suggested as suitable for nearly lattice-matched hetereojunctions with $\mathrm{CdTe}, \mathrm{GaSb}$, and AlSb, which find applications in the detection and 
generation of infrared radiation (Khadraoui et al., 2010). Tin disulfide, $\mathrm{SnS}_{2}$, with its mid-band gap of $2.18 \mathrm{eV}$ (Schlaf et al., 1997), is of interest for several applications such as window layer material in thin film solar cells (e.g. replacing toxic CdS) (Shi et al., 2013). This again motivates investigation of phase equilibria in the S-Sn system.

The present work aims to develop a full thermodynamic description of the S-Sn system using the CALPHAD (CALculation of PHase Diagram) technique that assesses available experimental data, supplemented by first-principles calculations, to produce a thermodynamically consistent description of phase equilibria (Liu, 2009). The idea with the CALPHAD technique is to assess parameters for functions describing the Gibbs energy of each phase relevant for the system. Once the thermodynamic description has been established, the equilibrium is obtained by minimizing the total Gibbs energy of the system accounting for all phases' contribution at the condition of question. The strength of this approach is the possibility to combine constituent subsystems (unary, binary, ternary etc.) to extrapolate into the multicomponent space. The description can then be used to interpolate and extrapolate among the process variables temperature $(T)$, composition $(x)$, and pressure $(P)$ parameters to rapidly explore operating conditions. The CALPHAD technique has been used extensively and successfully for many types of material systems. For example, it has been an important tool for alloy development of tool steels (Frisk et al., 2005; Lindwall and Frisk, 2013), Ni-base superalloys (Campbell et al., 2002; Kattner, 2002; Saunders et al., 2000) as well as to model complex behavior of oxides (Kjellqvist and Selleby, 2010; Kjellqvist et al., 2008; Lindwall et al., 2015) and cemented carbides (Ekroth et al., 2000; Frisk et al., 2005). Another example relevant for the current work, is the boron-magnesium (BMg) system (Liu et al., 2001b) where the developed description was used to calculated $T-x, P-x$ 
and $P-T$ diagrams for the purpose to guidance when selecting process condition for preparation of $\mathrm{MgB}_{2}$ superconductor films (Liu et al., 2001a).

Although some experimental information as well as some theoretical investigations are available for the thermodynamics of the S-Sn system, no CALPHAD description has hitherto been developed and hence, the information yet available is limited to the particular conditions of investigation. Based on CALPHAD modeling of the S-Sn system performed in the present work, the assessed $T-x, P-x$, and $P-T$ phase diagrams are generated and their applications are discussed.

\section{THERMODYNAMICS OF THE S-SN SYSTEM}

The type of phases, their amount and composition, that lead to the minimal Gibbs energy of the total system represents the equilibrium state of the system at given conditions and is obtained, in the case of the CALPHAD method, by minimization taking the energy contribution from all modeled phases into account. Experimentally, it is known that the S-Sn system contains four solid solution phases ( $\alpha-S, \beta-S, \alpha-S n$ and $\beta-S n)$, a liquid phase with two miscibility gaps, a gas phase and a number of $\mathrm{Sn}$ sulfides $\left(\mathrm{SnS}, \mathrm{Sn}_{2} \mathrm{~S}_{3}\right.$ and $\left.\mathrm{SnS}_{2}\right)$ with several allomorphs and very narrow homogeneity ranges. Hence, these are the phases that are modeled in the present work. Due to limited data, only one stoichiometric sulfide at each sulfur composition for both $\operatorname{Sn}_{2} \mathrm{~S}_{3}$ and $\mathrm{SnS}_{2}$, and the two equimolar allomorphs, $\alpha$ - and $\beta-\mathrm{SnS}$ are modeled. For the liquid phase, the associated model (Lukas et al., 2007) is adopted with the fictive species SnS. The details are presented in the Supporting Information, including (i) the review of phase equilibria and thermochemical data in the literature; (ii) thermodynamic modeling of S-Sn system using the Thermo-Calc software (Andersson et al., 2002); (iii) first-principles calculations of equilibrium properties for elements and compounds in the S-Sn system using the Vienna Ab-initio 
Simulation Package (VASP) code (Kresse and Furthmüller, 1996); and (iv) the modeling parameters and first-principles results.

Figure 1 compares the calculated temperature-composition $(T-x)$ phase diagram at 1 bar pressure with the reported experimental data (Albers and Schol, 1961; Anderson and Ridge, 1943; Biltz and Mecklenburg, 1909; Moh, 1969). The calculated diagram is a result of a Gibbs energy minimization where the elemental phases ( $\alpha-\mathrm{S}, \beta-\mathrm{S}, \alpha-\mathrm{Sn}$ and $\beta-\mathrm{Sn}$ ), the liquid, and the intermediate compounds $\mathrm{SnS}$ ( $\alpha-\mathrm{SnS}$ and $\beta-\mathrm{SnS}$ ), $\mathrm{Sn}_{2} \mathrm{~S}_{3}$ and $\mathrm{SnS}_{2}$ are included; i.e. the gas phase has not been incorporated. The experimental invariant transition temperatures and compositions are listed in Table 1 in comparison to the values calculated using the developed CALPHAD description. This table shows that the assessed $T-x$ phase diagram reproduces the experimental observations within the experimental uncertainty with one exception. The invariant reaction associated with liquid (L) and $\mathrm{SnS}_{2}$, on the S-rich side of the diagram (i.e. $\mathrm{L}_{2} \leftrightarrow \mathrm{L}_{3}+\mathrm{SnS}_{2}$ in Figure 1) shows a slightly higher calculated temperature (1133 K) than the measured value (1114 K) (Moh, 1969).

A transition with a difference between the experimental and assessed values but within the experimental uncertainty is the measured temperature for the eutectic reaction $\mathrm{L}_{2} \leftrightarrow \mathrm{SnS}+\mathrm{Sn}_{2} \mathrm{~S}_{3}$ at $~ 55$ at.\% sulfur (Albers and Schol, 1961; Karakhanova et al., 1966; Moh, 1969), with the three measured values higher than the calculated one $(967 \mathrm{~K})$. The latter deviation is accepted in the optimization on the basis of the large scatter in the experimental measurements; see details in Table 1. In the case of the discrepancy for the invariant reaction associated with the liquid (L) and $\mathrm{SnS}_{2}$ on the S-rich side, it is argued that only one set of data is available and that the high volatility of sulfur can lead to significant experimental error. 
Figure 2 illustrates the predicted $T-x$ phase diagrams at three different pressures ( 1 bar, 1 mbar, and 0.001 mbar). In the calculations for these diagrams, a description of the Gibbs energy of the gas phase is also incorporated in the minimization to find the equilibrium, in addition to the

phases included in Figure 1. The gas phase is treated as ideal, see Supporting Information, and the species $\mathrm{S}, \mathrm{S}_{2}, \mathrm{~S}_{3}, \mathrm{~S}_{4}, \mathrm{~S}_{5}, \mathrm{~S}_{6}, \mathrm{~S}_{7}, \mathrm{~S}_{8}, \mathrm{Sn}$, and $\mathrm{Sn}_{2}, \mathrm{SnS}, \mathrm{SnS}_{2}$, and $\mathrm{Sn}_{2} \mathrm{~S}_{2}$ are included, using the Gibbs Energy recommendations provided in the SGTE Dubstance Database ("SGTE Substances Database version 4," 2008). For the pressure of 1 bar (Figure 2a), the gas phase is stable above $\sim 735 \mathrm{~K}$ on the S-rich side, which is a temperature similar to the experimentally measured boiling temperature for pure sulfur (717.8 K) (Meyer, 1976). As the pressure decreases, the stability region for gas increases and the sublimation temperature for the compounds decreases (Figures $2 b$ and $2 c)$. Note that the order of the sublimation temperatures for the $\mathrm{SnS}_{2}$ and the $\mathrm{Sn}_{3} \mathrm{~S}_{2}$ compounds changes as the pressure is decreased. $\mathrm{SnS}_{2}$ is stable up to a higher temperature compared to the $\mathrm{Sn}_{2} \mathrm{~S}_{3}$ at higher pressure, whereas $\mathrm{Sn}_{2} \mathrm{~S}_{3}$, due to its lower sulfur content, is the thermally more stable sulfide at lower pressure.

\section{APPLICATIONS AND DISCUSSION}

As discussed in the Introduction, a motivation for developing a thermodynamic model describing phase equilibria in the S-Sn system is to provide guidance when growing and annealing tin sulfide films. Furthermore, synthesis of CZTS materials often involves a high temperature annealing step while avoiding decomposition of the CZTS phase. Thus mapping the stability ranges as a function of temperature, pressure and ambient gas phase composition that, at least, stabilizes the CZTS decomposition product $\mathrm{SnS}$ is needed. A typical annealing temperature for 
CZTS films is about $823 \mathrm{~K}$, and in Figure 3, a $P-x$ diagram for the $\mathrm{S}-\mathrm{Sn}$ system is provided at this temperature. This $P-x$ phase diagram is calculated using the thermodynamic description of the S-Sn system presented in the Supporting Information, and the diagram indicates the stable phases as pressure and composition combinations are varied at $823 \mathrm{~K}$. The phase relations and phase compositions depend strongly on the $\mathrm{S} / \mathrm{Sn}$ ratio in the system. For sulfur contents below 50 at. $\%$, the liquid phase is stable over the whole investigated pressure range; at lower pressures it is stable together with the gas phase and at higher pressures it is stable together with the $\alpha-\operatorname{SnS}$. If the composition is on the $\mathrm{S}$-rich side, the three sulfide compounds are in equilibrium with the gas phase except for the two two-phase regions " $\alpha-\mathrm{SnS}+\mathrm{SnS}_{2}$ " and " $\mathrm{SnS}_{2}+\mathrm{Sn}_{2} \mathrm{~S}_{3}$ " at higher pressure.

The minimum pressure required to stabilize the tin monosulfide, $\alpha-\mathrm{SnS}$, is $2.4 \times 10^{-3} \mathrm{mbar}$ according to the calculation and occurs at the $\mathrm{S} / \mathrm{Sn}$ ratio of $1: 1$. This can be compared with the experimental vapor pressure of pure $\mathrm{SnS}$ at $823 \mathrm{~K}$ which is $2.5 \times 10^{-3} \mathrm{mbar}$ in accordance to the measurements by (Piacente et al., 1991). With increasing S content; i.e. as the S/Sn ratio changes towards the S-rich side, the minimum total pressure required to stabilize the $\mathrm{SnS}$ increases. This is due to larger partial pressure of tin that is required to meet the increased partial pressure of sulfur that the increased sulfur content leads to. Consequently, the total pressure increases. As the chemical activity of sulfur is high enough, the S-richer compound $\mathrm{Sn}_{2} \mathrm{~S}_{3}$ becomes stable which, at $823 \mathrm{~K}$, occurs at the total pressure of $1.4 \times 10^{-2}$ mbar. At an even higher sulfur activity, the $\mathrm{SnS}_{2}$ compound can become stable. This occurs at the total pressure of 0.776 mbar. In this way the stability regions "gas $(\mathrm{G})+\alpha-\mathrm{SnS}$ ", "G $+\mathrm{Sn}_{2} \mathrm{~S}_{3}$ " and "G $+\mathrm{SnS}_{2}$ " at $823 \mathrm{~K}$ are identified in the $P$ - $x$ diagram as shown in Figure 3. 
In the work by (Banai et al., 2015), the present CALPHAD description is utilized to calculate $P$ - $x$ phase diagrams such as the ones in Figure 3, but at 573, 473 and 573 K. (Banai et al., 2015) prepared $\alpha$-SnS thin films by sputtering from a $\mathrm{SnS}_{2}$ target followed by annealing in an atmosphere close to vacuum $\left(\leq 10^{-6} \mathrm{mbar}\right)$ to transform the S-rich film into $\alpha$-SnS by sulfur evaporation. As expected, the resulting thin film microstructure was strongly correlated to the annealing conditions and the different outcomes could be understood by studying calculated $P-x$ phase diagrams. It was concluded that a temperature of approximately $673 \mathrm{~K}$ was most appropriate for the current experimental setup $\left(\leq 10^{-6} \mathrm{mbar}\right)$.

The above discussion concerns the pressure required for stabilizing Sn sulfides; i.e. not the CZTS phase. For CZTS, (Scragg et al., 2011) combined experimental investigations with a kinetic model to determine the gas ambient conditions that establish dynamic equilibrium at the CZTS surface. Their results suggest that the product $P^{\mathrm{c}}(\mathrm{SnS}) \cdot P^{\mathrm{c}}\left(\mathrm{S}_{2}\right)^{1 / 2}$, where $P^{\mathrm{c}}(\mathrm{SnS})$ and $P^{\mathrm{c}}\left(\mathrm{S}_{2}\right)$ are the partial pressures of $\mathrm{SnS}$ and $\mathrm{S}_{2}$ in gas, should be $(3.8 \pm 1.2) \cdot 10^{-5} \mathrm{mbar}^{3 / 2}$ or greater at $823 \mathrm{~K}$ to ensure stability of the CZTS phase. Here, $P^{\mathrm{c}}(\mathrm{SnS})$ and $P^{\mathrm{c}}\left(\mathrm{S}_{2}\right)$ are the partial pressures of $\mathrm{SnS}$ and $\mathrm{S}_{2}$ in the gas above CZTS. In their model, they assumed that $\mathrm{SnS}$ first forms as a solid phase on the CZTS surface and further, assumed that the value of $P^{\mathrm{c}}(\mathrm{SnS})$ thus could be taken to be the same as the equilibrium pressure over a pure $\mathrm{SnS}$ sulfide surface, $P(\operatorname{SnS})$, which had been previously measured (Piacente et al., 1991). By experimentally determine the extent of the CZTS decomposition at known $\mathrm{SnS}$ and $\mathrm{S}_{2}$ partial pressures, they could then estimate a critical value for the additional $S_{2}$ pressure, $P^{c}\left(S_{2}\right)$, required for stabilizing CZTS. The S-Sn description developed here could be used to further refine such an empirical model as undesired approximations due to limited thermodynamic data available in the literature could be avoided. 
For example, the value for $P(S n S)$ can be obtained at any temperature of importance using the present description. For ultimate control of CZTS process parameters, however, a complete thermodynamic description of the CZTS/CZTSSe system would be required and the binary S-Sn subsystem developed here is only one of the necessary step stones for the development of this multicomponent description.

Deposition of a single-phase film, $\mathrm{SnS}, \mathrm{SnS}_{2}$ or $\mathrm{Sn}_{2} \mathrm{~S}_{3}$, becomes favorable when the growth conditions (substrate temperature together with sulfur and tin overpressures) fall within the window where the thermodynamically stable phases are the desired sulfide and the gas phase. Within this growth window, the sulfide does not decomposes and the excess tin and sulfur do not condense on the film surface and thus, the formation of the film is adsorption-controlled. The single-phase growth window can be inferred from $T-x$ and $P-x$ phase diagrams like the ones shown in Figures 2 and 3, but is more clearly illustrated in a $P$ - $T$ diagram. In this case, the overall $\mathrm{S} / \mathrm{Sn}$ ratio is kept constant, similar to our early work on the adsorption-controlled growth window of the $\mathrm{MgB}_{2}$ superconductor film (Liu et al., 2001a, 2001b). Three such diagrams are shown in Figure 4 for different compositions on the S-rich side; i.e. at 55, 75, and 95 at.\% sulfur. For S/Sn combinations on the Sn-rich side, the liquid phase is stable for most conditions above the melting point of tin. This is true also at lower pressures which, for example, can be seen in Figure $2 \mathrm{c}$, where the $T$ - $x$ phase diagrams at $10^{-3} \mathrm{mbar}$, is shown. The boiling temperature of tin is high (around $2860 \mathrm{~K}$ at 1 bar and around $1340 \mathrm{~K}$ at $10^{-3} \mathrm{mbar}$ ) and to have solid $\alpha$-SnS stable together with only gas at conditions regarded as achievable experimentally cannot be expected. $\mathrm{S} / \mathrm{Sn}$ ratios should therefore be avoided in preparation routes where the presence of liquid would be detrimental. The presence of a liquid phase, if completely wetting, would present a mass transfer barrier during film growth to limit growth rate and likely leave the surface rough upon 
cooling to room temperature due to depletion of sulfur from the liquid phase as $\mathrm{SnS}$ forms and eventual solidification of a second phase of nearly pure tin close to its melting temperature. If the liquid partially wets the growth surface, the possibility of growing nanostructure by a vaporliquid-solid mechanism exists. This is the case for adsorption-controlled growth of single-phase films by e.g. thermal evaporation and thus, only diagrams for S-rich system are discussed here.

From a thermodynamic perspective, the window beneficial for growing and stabilizing single $\mathrm{SnS}_{2}$ films is relatively large. For $\mathrm{S} / \mathrm{Sn}$ ratios equal to or above the stoichiometric $\mathrm{SnS}_{2}$ composition, the lower boundary of the stability window for $\mathrm{SnS}_{2}$ and gas; i.e. the boundary between the phase region marked "gas $+\mathrm{Sn}_{2} \mathrm{~S}_{3}$ " and "gas $+\mathrm{SnS}_{2}$ " in Figure $4 \mathrm{~b}$ and $4 \mathrm{c}$, and is approximately given by,

$$
\log (P)=-9413 / T+8.321
$$

where $P$ is in bar and $T$ is in Kelvin. As long as the growth condition or annealing conditions lie above this boundary, a single phase $\mathrm{SnS}_{2}$ is thermodynamically stable. If the $\log (P)-1 / T$ combination resides below this line, $\mathrm{Sn}_{2} \mathrm{~S}_{3}$ or $\mathrm{SnS}$ phases may form. The logarithm of pressure can be approximated as a linear function of $1 / T$ due to the ideal behavior of the gas phase for which an Arrhenius relationship is to be expected.

The growth conditions beneficial for growth of $\mathrm{SnS}$ films are much more restricted. The $\mathrm{S} / \mathrm{Sn}$ ratio should be equal or just above the stoichiometric $\mathrm{SnS}$ composition for the stability window to be wide, see the regions "gas $+\alpha$-SnS" and "gas $+\beta-\mathrm{SnS}$ " in Figure 4a. The further away from the SnS composition, the narrower the stability window becomes (e.g. compare the extent of the "gas $+\alpha-\mathrm{SnS}$ " and "gas $+\alpha-\mathrm{SnS}$ " regions in Figure $4 \mathrm{a}$ and $4 \mathrm{~b}$, and the risk for formation 
of $\mathrm{SnS}_{2}$ or $\mathrm{Sn}_{2} \mathrm{~S}_{3}$ increases. The upper growth window boundary for $\mathrm{SnS}$ from gas is approximately given by,

$$
\log (P)=-10859 / T+8.340
$$

which is valid for a pressure and temperature below below $1.27 \cdot 10^{-3}$ bar and $967 \mathrm{~K}$ for $\beta$-SnS and $8.5 \cdot 10^{-5}$ bar and $875 \mathrm{~K}$ for $\alpha-\mathrm{SnS}$, respectively, see Figure 4a. The lower growth window boundary for $\mathrm{SnS}$ is approximately given by,

$$
\log (P)=-A / T+B=-11041 / T+7.808
$$

This boundary represents solid $\mathrm{SnS}$ in equilibrium with gas and the values of the relationship can be compared to previous reported $A$ and $B$ values based on experimental measurements of the vapor pressure of $\mathrm{SnS}$ over solid $\mathrm{SnS}$; e.g. the values $A=10794$ and $B=7.456$ (from 875 to 1153 K) reported by (Sharma and Chang, 1986) which are comparable to the calculated present values. For more S-rich compositions, the formation of $\mathrm{SnS}$ is not thermodynamically possible at all, see Figure 4c. Of course this analysis considers only the equilibrium conditions, and the reaction or mass transfer limitation during growth of the thin film would change the details of the phase stability windows.

\section{SUMMARY}

A full thermodynamic description of the S-Sn system has been developed using the CALPHAD approach provided with input from the phase equilibrium data in the literature and firstprinciples calculations reported in this work. Using this description, thermodynamic stability regions of $\mathrm{Sn}$ sulfides $\left(\mathrm{SnS}, \mathrm{SnS}_{2}\right.$, and $\left.\mathrm{Sn}_{2} \mathrm{~S}_{3}\right)$ are identified and illustrated by temperaturecomposition $(T-x)$, pressure-composition $(P-x)$ and pressure-temperature $(P-T)$ phase diagrams calculated. These diagrams guide the selection of appropriate conditions for adsorption- 
controlled growth of and annealing conditions for single-phase $\mathrm{SnS}, \mathrm{SnS}_{2}$, and $\mathrm{Sn}_{2} \mathrm{~S}_{3}$ films as well as post-deposition annealing conditions for annealing of CZTS-based films while avoiding loss of SnS. 


\section{ASSOCIATED CONTENT}

\section{Supporting Information}

Details of experimental information of the S-Sn binary system available in the literature, firstprinciples calculations together with structural information, thermodynamic modeling and predicted properties are presented in the Supporting Information. This material is accessible online and free of charge at http://pubs.acs.org.

\section{AUTHOR INFORMATION}

\section{Corresponding Author}

*E-mail: gretalindwall@gmail.com

\section{Notes}

The authors declare no competing financial interest.

\section{ACKNOWLEDGMENTS}

This work was financially supported by the National Science Foundation (NSF) with Grant Nos. CHE-1230924 and CHE-1230929 and the Gladys Snyder Grant from the College of Earth and Mineral Sciences at the Pennsylvania State University. First-principles calculations were carried out partially on the LION clusters by the Materials Simulation Center and the Research Computing and Cyberinfrastructure Group at the Pennsylvania State University, partially on the resources of NERSC supported by the Office of Science of the U.S. Department of Energy under contract No. DE-AC02-05CH11231, and partially on the resources of XSEDE supported by NSF with Grant No. ACI-1053575. 


\section{REFERENCES}

Ahmed, S., Reuter, K.B., Gunawan, O., Guo, L., Romankiw, L.T., Deligianni, H., 2012. A high efficiency electrodeposited Cu2ZnSnS4 solar cell. Adv. Energy Mater. 2, 253-259.

Albers, W., Haas, C., Vink, H.J., Wasscher, J.D., 1961. Investigations on SnS. J. Appl. Phys. 32, $2220-2225$.

Albers, W., Schol, K., 1961. The P-T-X phase diagram of the system Sn-S. Philips Res. Reports $16,329-342$.

Anderson, J.S., Ridge, M.J., 1943. The system tin-stannous sulphide. J. Chem. Soc. Faraday Trans. 39, 98-102.

Andersson, J.-O., Helander, T., Höglund, L., Shi, P., Sundman, B., 2002. Thermo-Calc \& DICTRA, computational tools for materials science. Calphad - Comput. Coupling Phase Diagrams Thermochem. 26, 273-312.

Avellaneda, D., Delgado, G., Nair, M.T.S., Nair, P.K., 2007. Structural and chemical transformations in $\mathrm{SnS}$ thin films used in chemically deposited photovoltaic cells. Thin Solid Films 515, 5771-5776.

Bade, B.P., Garje, S.S., Niwate, Y.S., Afzaal, M., O’Brien, P., 2008. Tribenzyltin (IV) chloride Thiosemicarbazones: Novel Single Source Precursors for Growth of SnS Thin Films. Chem. Vap. Depos. 14, 292-295.

Banai, R.E., Cordell, J.C., Lindwall, G., Tanen, N.J., Shang, S.-L., Nasr, J.R., Liu, Z.-K., Brownson, J.R.S., Horn, M.W., 2015. Control of Phase in Tin Sulfide This Films Produced via Sputtering of SnS2 Target with Post-deposition Annealing. Accept. by J. Electron. Mater. doi:10.1007/s11664-015-4137-2

Banai, R.E., Lee, H., Motyka, M.A., Chandrasekharan, R., Podraza, N.J., Brownson, J.R.S., Hom, M.W., 2013. Optical Properties of Sputtered SnS Thin Films for Photovoltaic Absorbers. IEEE J. Photovoltaics 3, 1084-1089.

Barone, G., Chaplin, T., Hibbert, T.G., Kana, A.T., Mahon, M.F., Molloy, K.C., Worsley, I.D., Parkin, I.P., Price, L.S., 2002. Synthesis and thermal decomposition studies of homo-and heteroleptic tin (IV) thiolates and dithiocarbamates: molecular precursors for tin sulfides. J. Chem. Soc. Dalt. Trans. 1085-1092.

Barone, G., Hibbert, T.G., Mahon, M.F., Molloy, K.C., Price, L.S., Parkin, I.P., Hardy, A.M.E., Field, M.N., 2001. Deposition of tin sulfide thin films from tin (IV) thiolate precursors. J. Mater. Chem. 11, 464-468. 
Biacchi, A.J., Vaughn, D.D., Schaak, R.E., 2013. Synthesis and Crystallographic Analysis of Shape-Controlled SnS Nanocrystal Photocatalysts: Evidence for a Pseudotetragonal Structural Modification. J. Am. Chem. Soc. 135, 11634-11644.

Biltz, W., 1908. Notizen über schmelzen und sublimieren einiger sulfide. Zeitschrift fur Anorg. und Allg. Chemie 59, 273-284.

Biltz, W., Mecklenburg, W., 1909. Über die Zustandsdiagramme von Zinn mit Schwefel, Selen und Tellur. Zeitschrift fur Anorg. und Allg. Chemie 64, 226-235.

Buchenau, C., Cardona, M., Pollak, F.H., 1971. Raman scattering in gray tin. Phys. Rev. B 3, 1243.

Calixto-Rodriguez, M., Martinez, H., Sanchez-Juarez, A., Campos-Alvarez, J., Tiburcio-Silver, A., Calixto, M.E., 2009. Structural, optical, and electrical properties of tin sulfide thin films grown by spray pyrolysis. Thin Solid Films 517, 2497-2499.

Campbell, C.., Boettinger, W.., Kattner, U.., 2002. Development of a diffusion mobility database for Ni-base superalloys. Acta Mater. 50, 775-792.

Ekroth, M., Dumitrescu, L.F.S., Frisk, K., Jansson, B., 2000. Development of a thermodynamic database for cemented carbides for design and processing simulations. Metall. Mater. Trans. B 31, 615-619.

Frisk, K., Bratberg, J., Markström, A., 2005. Thermodynamic modelling of the M6C carbide in cemented carbides and high-speed steel. Calphad 29, 91-96.

Green, M.A., Emery, K., Hishikawa, Y., Warta, W., Dunlop, E.D., 2014. Solar cell ef fi ciency tables ( version 44 ). Prog. Photovoltaics Res. Appl. 22, 701-710.

Hartman, K., Johnson, J.L., Bertoni, M.I., Recht, D., Aziz, M.J., Scarpulla, M.A., Buonassisi, T., 2011. SnS thin-films by RF sputtering at room temperature. Thin Solid Films 519, 74217424.

Hibbert, T.G., Mahon, M.F., Molloy, K.C., Price, L.S., Parkin, I.P., 2001. Deposition of tin sulfide thin films from novel, volatile (fluoroalkythiolato) tin (IV) precursors. J. Mater. Chem. 11, 469-473.

Johnson, J.B., Jones, H., Latham, B.S., Parker, J.D., Engelken, R.D., Barber, C., 1999. Optimization of photoconductivity in vacuum-evaporated tin sulfide thin films. Semicond. Sci. Technol. 14, 501.

Karakhanova, M.I., Pashinkin, A.S., Novoselova, A. V, 1966. On the Tin-Sulfur Fusibility Curve. Inorg. Mater. 2, 991-996. 
Katagiri, H., Jimbo, K., Yamada, S., Kamimura, T., Maw, W.S., Fukano, T., Ito, T., Motohiro, T., 2008. Enhanced conversion efficiencies of $\mathrm{Cu} 2 \mathrm{ZnSnS4-based} \mathrm{thin} \mathrm{film} \mathrm{solar} \mathrm{cells} \mathrm{by}$ using preferential etching technique. Appl. Phys. Express 1, 41201.

Kattner, U.R., 2002. Construction of a thermodynamic database for Ni-base superalloys: A case study, in: Turchi, P.E.A., Gonis, A., Shull, R. (Eds.), CALPHAD and Alloy Thermodynamics, TMS. Warrendale, PA.

Khadraoui, M., Benramdane, N., Mathieu, C., Bouzidi, A., Miloua, R., Kebbab, Z., Sahraoui, K., Desfeux, R., 2010. Optical and electrical properties of thin films grown by spray pyrolysis. Solid State Commun. 150, 297-300.

Kjellqvist, L., Selleby, M., 2010. Thermodynamic Assessment of the Fe-Mn-O System. J. Phase Equilibria Diffus. 31, 113-134.

Kjellqvist, L., Selleby, M., Sundman, B., 2008. Thermodynamic modelling of the $\mathrm{Cr}-\mathrm{Fe}-\mathrm{Ni}-\mathrm{O}$ system. Calphad 32, 577-592.

Kodigala, S.R., 2014. Thin Film Solar Cells From Earth Abundant Materials: Growth and Characterization of $\mathrm{Cu} 2 \mathrm{ZnSn}(\mathrm{SSe}) 4$ Thin Films and Their Solar Cells. Elsevier, New York.

Koteeswara Reddy, N., Hahn, Y.B., Devika, M., Sumana, H.R., Gunasekhar, K.R., 2007. Temperature-dependent structural and optical properties of SnS films. J. Appl. Phys. 101, 093522.

Kresse, G., Furthmüller, J., 1996. Efficiency of ab-initio total energy calculations for metals and semiconductors using a plane-wave basis set. Comput. Mater. Sci. 6, 15-50.

Lindwall, G., Frisk, K., 2013. The effect of nitrogen on the coarsening rate of precipitate phases in iron-based alloys with chromium and vanadium: experimental and theoretical investigations. Int. J. Mater. Res. 104, 442-451.

Lindwall, G., Ross, A., Fang, H.Z., Liu, L.X., Liu, Z.-K., 2015. Thermodynamic Modeling of the Aluminum-Iron-Oxygen System.

Liu, Z.K., 2009. First-Principles Calculations and CALPHAD Modeling of Thermodynamics. J. Phase Equilibria Diffus. 30, 517-534.

Liu, Z.-K., Schlom, D.G., Li, Q., Xi, X.X., 2001a. Thermodynamics of the Mg-B system: Implications for the deposition of $\mathrm{MgB}_{2}$ thin films. Appl. Phys. Lett. 78, 3678.

Liu, Z.-K., Zhong, Y., Schlom, D.G., Xi, X.X., Li, Q., 2001b. Computational thermodynamic modeling of the Mg-B system. Calphad 25, 299-303.

Lukas, H.L., Fries, S.G., Sundman, B., 2007. Computational thermodynamics: the CALPHAD method. Cambridge University Press Cambridge. 
Mathews, N.R., Anaya, H.B.M., Cortes-Jacome, M.A., Angeles-Chavez, C., Toledo-Antonio, J.A., 2010. Tin sulfide thin films by pulse electrodeposition: structural, morphological, and optical properties. J. Electrochem. Soc. 157, H337-H341.

Meyer, B., 1976. Elemental sulfur. Chem. Rev. 76, 367-388.

Miles, R.W., Ogah, O.E., Zoppi, G., Forbes, I., 2009. Thermally evaporated thin films of SnS for application in solar cell devices. Thin Solid Films 517, 4702-4705.

Moh, G.H., 1969. The tin-sulfur system and related minerals. Neues Jahrb. für Mineral. 111, 227-263.

Nebesny, K.W., Collins, G.E., Lee, P.A., Chau, L.K., Danziger, J., Osburn, E., Armstrong, N.R., 1991. Organic/inorganic-molecular beam epitaxy: formation of an ordered phthalocyanine/tin (IV) sulfide heterojunction. Chem. Mater. 3, 829-838.

Noguchi, H., Setiyadi, A., Tanamura, H., Nagatomo, T., Omoto, O., 1994. Characterization of vacuum-evaporated tin sulfide film for solar cell materials. Sol. energy Mater. Sol. cells 35, $325-331$.

Ogah, O.E., Zoppi, G., Forbes, I., Miles, R.W., 2009. Thin films of tin sulphide for use in thin film solar cell devices. Thin Solid Films 517, 2485-2488.

Orr, R.L., Christensen, A.U., 1958. High Temperature Heat Contents of Stannous and Stannic Sulfides. J. Phys. Chem. 62, 124-125.

Pelabon, H., Moissan, M.H., 1906. On the Sulfides, Selenides and Tellurides of Tin. Compt. Rend 142, 1147-1149.

Piacente, V., Foglia, S., Scardala, P., 1991. Sublimation study of the tin sulphides SnS2, Sn2S3 and SnS. J. Alloys Compd. 177, 17-30.

Price, L.S., Parkin, I.P., Hardy, A.M.E., Clark, R.J.H., Hibbert, T.G., Molloy, K.C., 1999. Atmospheric pressure chemical vapor deposition of tin sulfides ( $\mathrm{SnS}, \mathrm{Sn} 2 \mathrm{~S} 3$, and $\mathrm{SnS} 2)$ on glass. Chem. Mater. 11, 1792-1799.

Redinger, A., Berg, D.M., Dale, P.J., Djemour, R., Guetay, L., Eisenbarth, T., Valle, N., Siebentritt, S., 2011a. Route Toward High-Efficiency Single-Phase Cu2ZnSn(S,Se)(4) Thin-Film Solar Cells: Model Experiments and Literature Review. Ieee J. Photovoltaics 1, 200-206.

Redinger, A., Berg, D.M., Dale, P.J., Siebentritt, S., 2011b. The consequences of kesterite equilibria for efficient solar cells. J. Am. Chem. Soc. 133, 3320-3. 
Romero, M.J., Du, H., Teeter, G., Yan, Y., Al-Jassim, M.M., 2011. Comparative study of the luminescence and intrinsic point defects in the kesterite $\mathrm{Cu} 2 \mathrm{ZnSnS} 4$ and chalcopyrite $\mathrm{Cu}(\mathrm{In}, \mathrm{Ga}) \mathrm{Se} 2$ thin films used in photovoltaic applications. Phys. Rev. B 84, 165324.

Sajeesh, T.H., Warrier, A.R., Kartha, C.S., Vijayakumar, K.P., 2010. Optimization of parameters of chemical spray pyrolysis technique to get $\mathrm{n}$ and p-type layers of SnS. Thin Solid Films $518,4370-4374$.

Sánchez-Juárez, A., Tiburcio-Silver, A., Ortiz, A., 2005. Fabrication of $\operatorname{SnS}<\operatorname{sub}>2</ \mathrm{sub}>/ \mathrm{SnS}$ heterojunction thin film diodes by plasma-enhanced chemical vapor deposition. Thin Solid Films 480, 452-456.

Saunders, N., Fahrmann, M., Small, C.J., 2000. Application of CALPHAD calculations to Nibased supperalloys, in: Green, K.A., Pollock, T.M., Kissinger, R.D. (Eds.), Supperalloys 2000, TMS. Warrendale, PA.

Schlaf, R., Armstrong, N.R., Parkinson, B.A., Pettenkofer, C., Jaegermann, W., 1997. Van der Waals epitaxy of the layered semiconductors SnSe2 and SnS2: morphology and growth modes. Surf. Sci. 385, 1-14.

Schubert, B., Marsen, B., Cinque, S., Unold, T., Klenk, R., Schorr, S., Schock, H., 2011. $\mathrm{Cu} 2 \mathrm{ZnSnS} 4$ thin film solar cells by fast coevaporation. Prog. Photovoltaics Res. Appl. 19, 93-96.

Scragg, J.J., Ericson, T., Kubart, T., Edoff, M., Platzer-Björkman, C., 2011. Chemical insights into the instability of $\mathrm{Cu} 2 \mathrm{ZnSnS} 4$ films during annealing. Chem. Mater. 23, 4625-4633.

SGTE Substances Database version 4, 2008.

Sharma, R.C., Chang, Y.A., 1986. The S- Sn (Sulfur-Tin) system. J. Phase Equilibria 7, 269273.

Shi, C., Yang, P., Yao, M., Dai, X., Chen, Z., 2013. Preparation of SnS2 thin films by closespaced sublimation at different source temperatures. Thin Solid Films 534, 28-31.

Shin, B., Gunawan, O., Zhu, Y., Bojarczuk, N.A., Chey, S.J., Guha, S., 2013. Thin film solar cell with $8.4 \%$ power conversion efficiency using an earth-abundant $\mathrm{Cu} 2 \mathrm{ZnSnS} 4$ absorber. Prog. Photovoltaics Res. Appl. 21, 72-76.

Shockley, W., Queisser, H.J., 1961. Detailed balance limit of efficiency of p-n junction solar cells. J. Appl. Phys. 32, 510-519.

Sinsermsuksakul, P., Heo, J., Noh, W., Hock, A.S., Gordon, R.G., 2011. Atomic layer deposition of tin monosulfide thin films. Adv. Energy Mater. 1, 1116-1125. 
Sinsermsuksakul, P., Sun, L., Lee, S.W., Park, H.H., Kim, S.B., Yang, C., Gordon, R.G., 2014. Overcoming Efficiency Limitations of SnS-Based Solar Cells. Adv. Energy Mater. 4.

Steinmann, V., Jaramillo, R., Hartman, K., Chakraborty, R., Brandt, R.E., Poindexter, J.R., Lee, Y.S., Sun, L., Polizzotti, A., Park, H.H., Gordon, R.G., Buonassisi, T., 2014. 3.88\% Efficient Tin Sulfide Solar Cells using Congruent Thermal Evaporation. Adv. Mater. 26, 7488-92.

Wang, W., Leung, K.K., Fong, W.K., Wang, S.F., Hui, Y.Y., Lau, S.P., Chen, Z., Shi, L.J., Cao, C.B., Surya, C., 2012. Molecular beam epitaxy growth of high quality p-doped SnS van der Waals epitaxy on a graphene buffer layer. J. Appl. Phys. 111, 93520.

Wang, W., Winkler, M.T., Gunawan, O., Gokmen, T., Todorov, T.K., Zhu, Y., Mitzi, D.B., 2014. Device Characteristics of CZTSSe Thin-Film Solar Cells with 12.6\% Efficiency. Adv. Energy Mater. 4, 1301465.

Wiedemeier, H., Csillag, F.J., 1979. Equilibrium sublimation and thermodynamic properties of SnS. Thermochim. Acta 34, 257-265. 


\section{FIGURES}

(a)

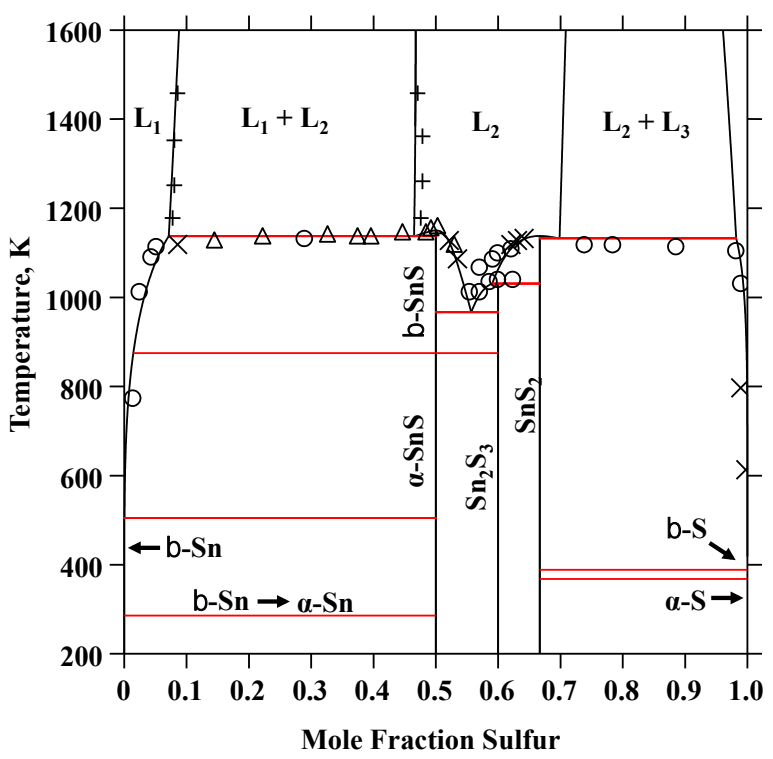

(b)

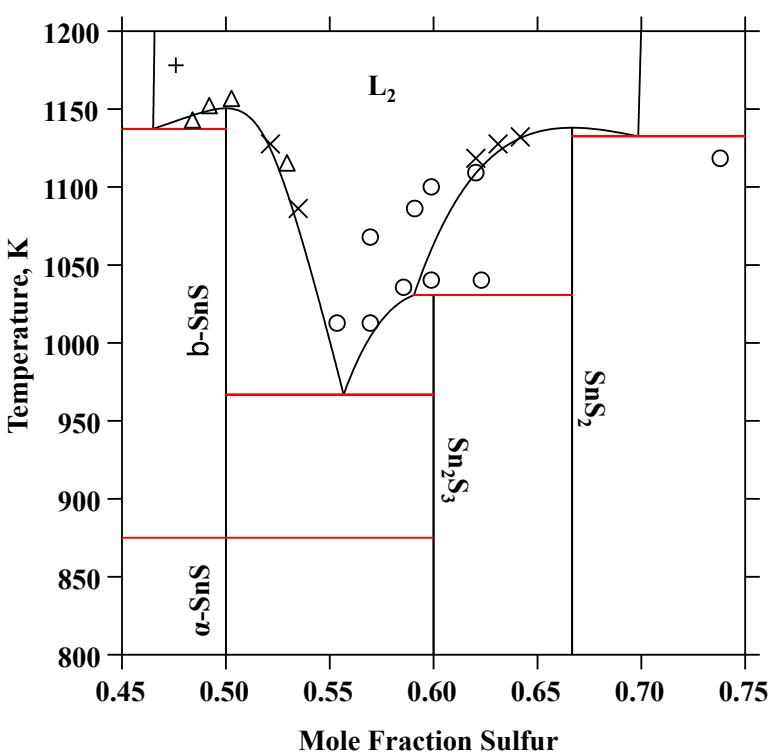

Figure 1: Calculated temperature-composition phase diagram for the $\mathrm{S}-\mathrm{Sn}$ system compared to experimental data; $\bigcirc($ Moh, 1969), + (Anderson and Ridge, 1943), $\Delta$ (Biltz and Mecklenburg, 1909) and $\times$ (Albers and Schol, 1961). The phase diagram is calculated at the pressure 1 bar and without inclusion of the gas phase. The figure to the right (b) is an enlargement of the central part of the phase diagram to the left (a), and the letter L indicates liquid. Red solid lines represent invariant transformation temperatures. 
(a)

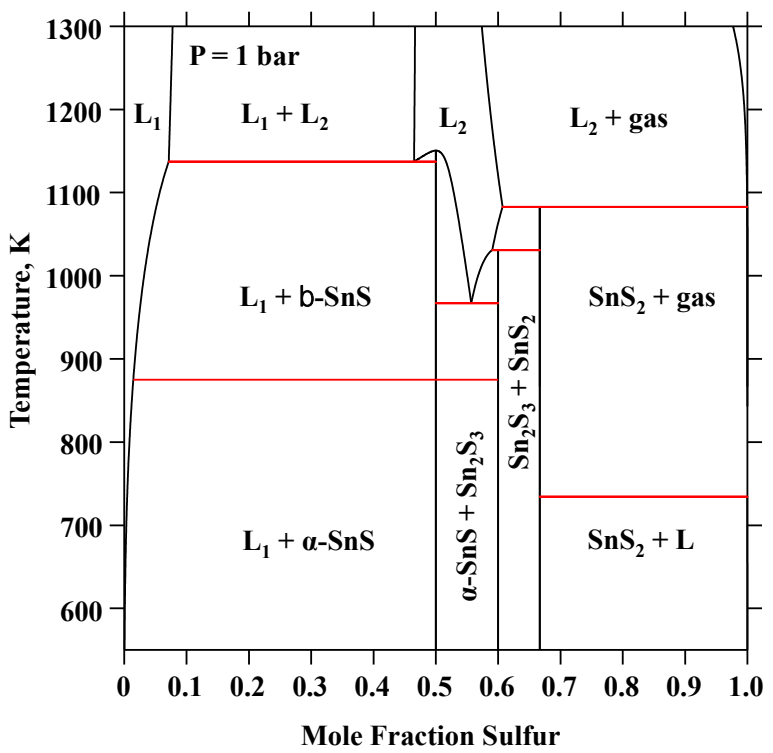

(c)

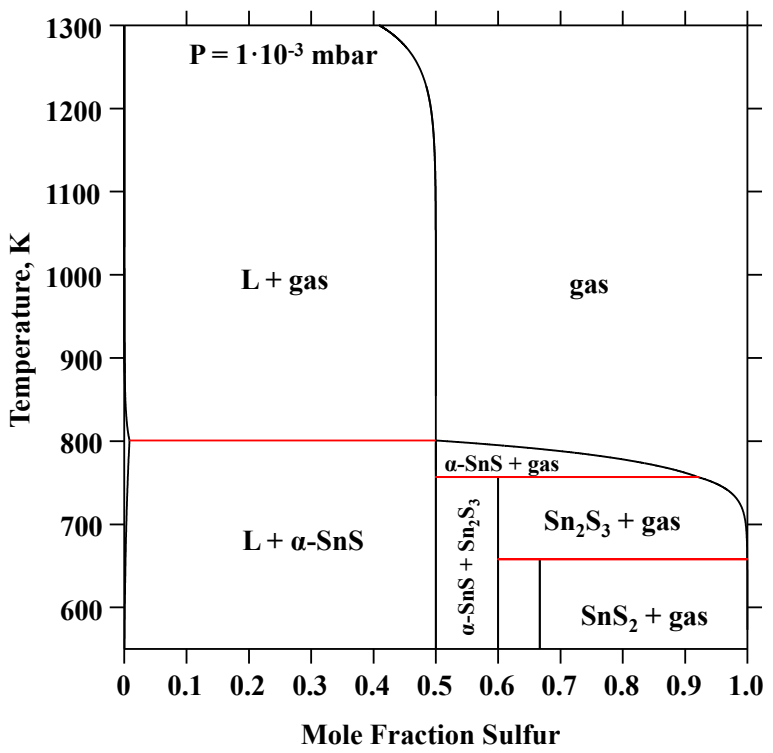

(b)

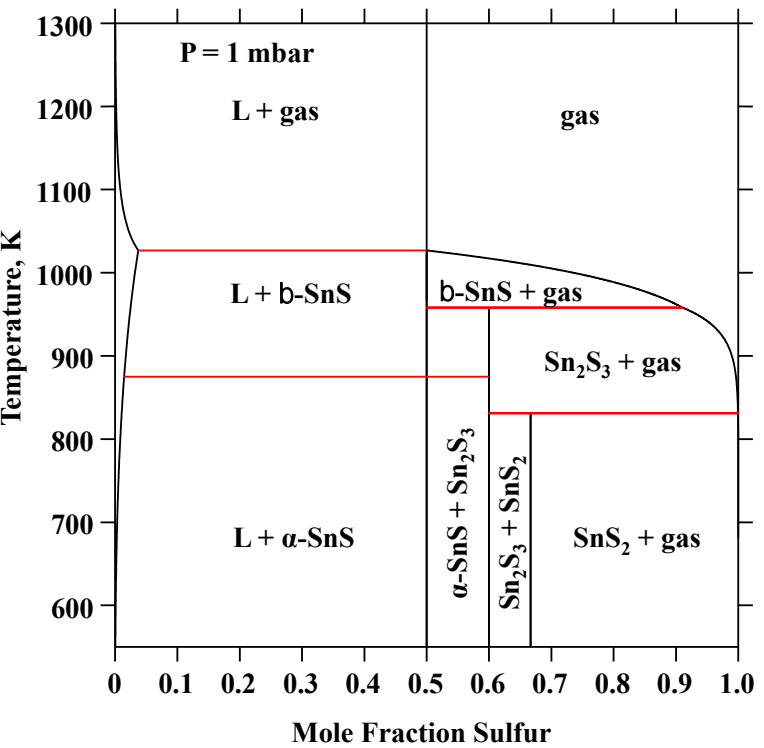

Figure 2: Calculated temperature-composition phase diagrams for the $\mathrm{S}-\mathrm{Sn}$ system, including the gas phase, at constant pressures of (a) 1 bar, (b) 1 mbar, and (c) $10^{-3}$ mbar, with L denoting liquid. 


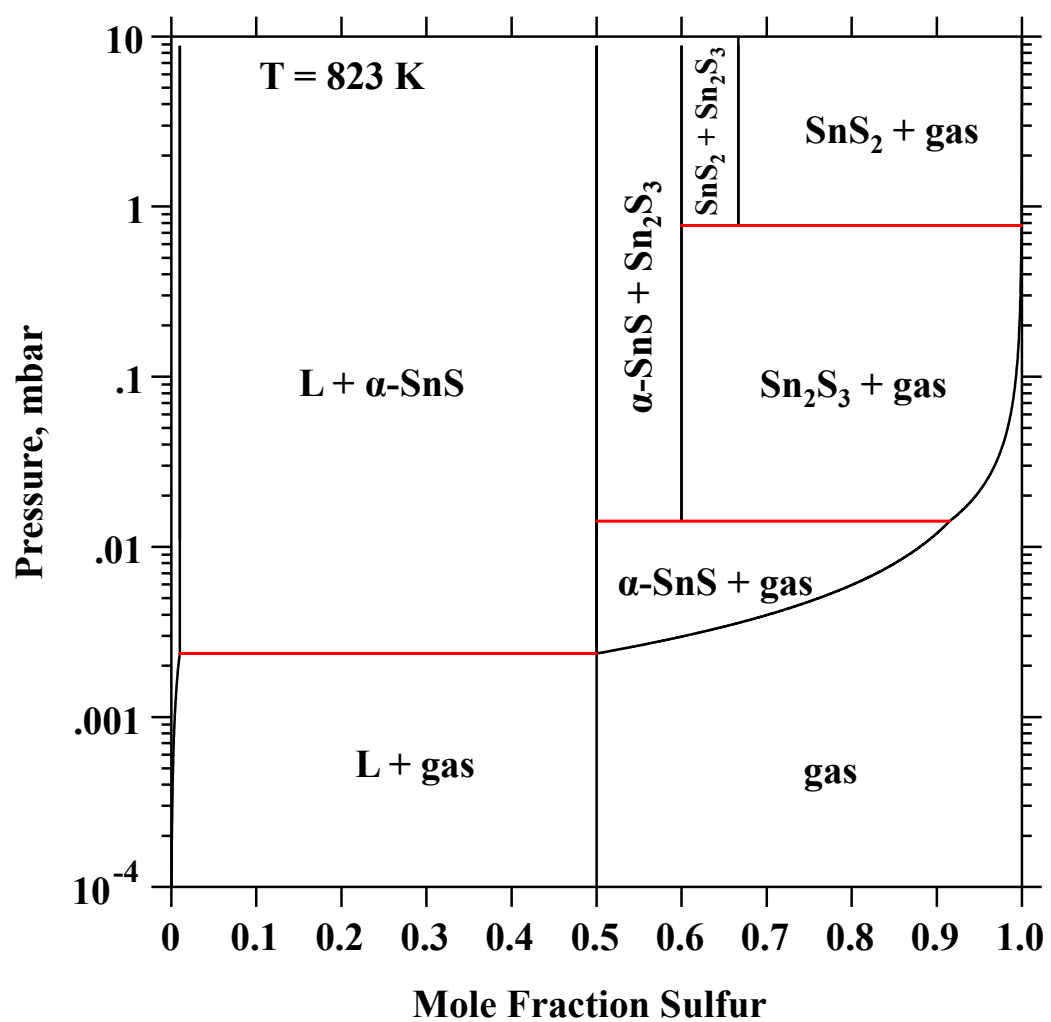

Figure 3: Calculated pressure-composition phase diagram at a typical annealing emperature of $823 \mathrm{~K}$ used in CZTS/CZTSSe film growth (Scragg et al., 2011), with L denoting liquid. 
(a)

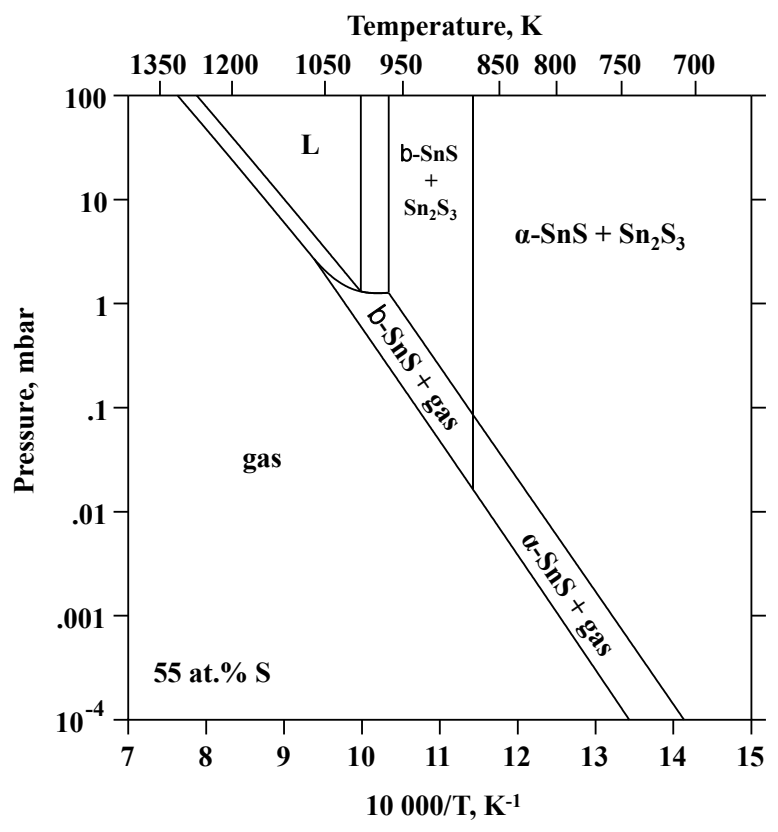

(c)

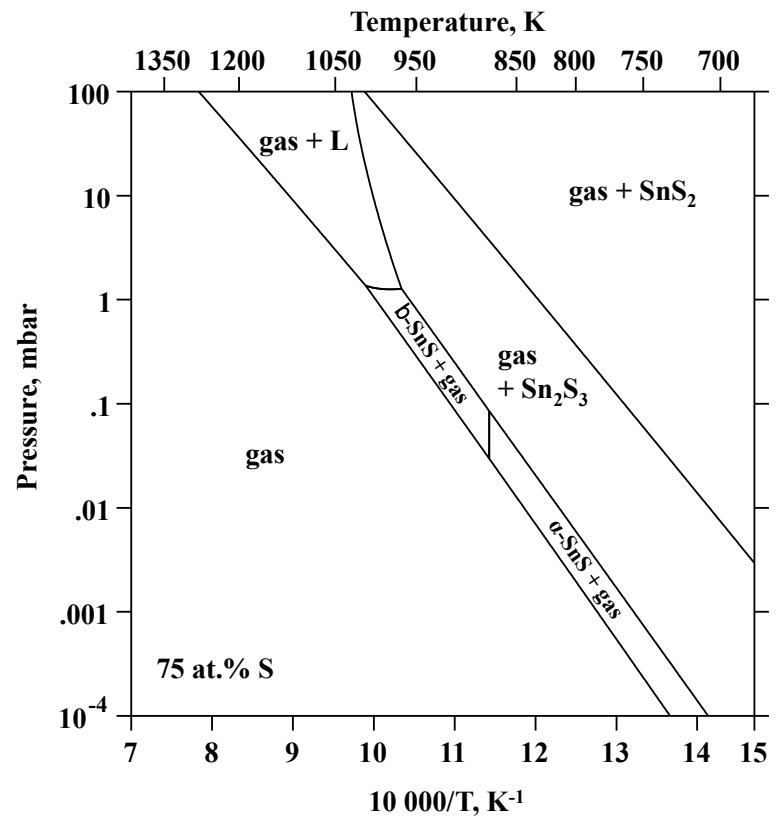

Figure 4: Calculated pressure-temperature phase diagrams for the sulfur concentrations of (a) 55 at.\%, (b) 75 at.\%, and (c) 95 at.\%, with L sdenoting liquid. 


\section{TABLES}

Table 1: Calculated temperatures $(T$, in $\mathrm{K})$ and compositions $\left(x_{S}\right.$, in at- $\left.\%\right)$ for invariant reactions and melting $\left(T_{m}\right)$ compared to experimental temperatures and compositions for the S-Sn system.

\begin{tabular}{|c|c|c|c|c|}
\hline Reactions & & $x_{S}$ & & $T$ \\
\hline \multirow[t]{2}{*}{$\mathrm{L}_{1} \square \beta \mathrm{Sn}+\alpha-\mathrm{SnS}$} & - & 0 & 50 & 505 \\
\hline & - & - & $50^{\mathrm{i}}$ & $504^{\mathrm{i}}$ \\
\hline \multirow[t]{2}{*}{$\mathrm{L}_{2} \square \mathrm{L}_{1}+\beta-\mathrm{SnS}$} & 46.5 & 7.1 & 50.0 & 1137 \\
\hline & $48.0^{12,22}$ & $7.5^{22}$ & $50^{\mathrm{i}, \mathrm{k}, \mathrm{r}}$ & $1128,{ }^{\mathrm{r}} 1131^{\mathrm{k}}, 1133^{\mathrm{j}, \mathrm{p}}$ \\
\hline \multirow[t]{2}{*}{$\mathrm{L}_{2} \square \beta-\mathrm{SnS}+\mathrm{Sn}_{2} \mathrm{~S}_{3}$} & 55.7 & 50.0 & 60.0 & 967 \\
\hline & $55^{\mathrm{k}, \mathrm{p}} 55.6^{\mathrm{j}}$ & $50^{\mathrm{j}, \mathrm{l,q}}$ & $57,{ }^{\mathrm{k}} 60^{\mathrm{j}, \mathrm{p}}$ & $978,{ }^{1} 1013,{ }^{\mathrm{j}} 1011^{\mathrm{q}}$ \\
\hline \multirow[t]{2}{*}{$\mathrm{L}_{2}+\mathrm{SnS}_{2} \square \mathrm{Sn}_{2} \mathrm{~S}_{3}$} & 59.1 & 66.67 & 60.0 & 1031 \\
\hline & $56.5,{ }^{\mathrm{j}} 59^{\mathrm{k}}$ & $66.67^{\mathrm{j}, \mathrm{k}}$ & $60^{\mathrm{j}, \mathrm{k}}$ & $1018,{ }^{\mathrm{j}}, 1033^{1}$ \\
\hline \multirow[t]{2}{*}{$\mathrm{L}_{2} \square \mathrm{SnS}_{2}+\mathrm{L}_{3}$} & 69.8 & 66.67 & 98.2 & 1132 \\
\hline & $70^{\mathrm{j}}$ & $66.67^{j}$ & $98^{\mathrm{j}}$ & $1114^{\mathrm{j}}$ \\
\hline \multirow[t]{2}{*}{$\mathrm{L}_{3} \square \mathrm{SnS}_{2}+\beta \mathrm{S}$} & 100 & 66.67 & 100 & 388 \\
\hline & $\leq 100^{\mathrm{j}}$ & $66.67^{\mathrm{j}}$ & $<100^{\mathrm{j}}$ & $385^{\mathrm{j}}$ \\
\hline \multirow[t]{2}{*}{$\mathrm{T}_{\mathrm{m}}$ for $\beta-\mathrm{SnS}$} & 50.0 & & & 1150 \\
\hline & & & & $1143,{ }^{\mathrm{n}} 1148,{ }^{\mathrm{k}} 1153{ }^{\mathrm{j}, \mathrm{l}, \mathrm{m}} 1155^{\circ}$ \\
\hline \multirow[t]{2}{*}{$\mathrm{T}_{\mathrm{m}}$ for $\mathrm{Sn}_{2} \mathrm{~S}_{3}$} & 60.0 & & & 1031 \\
\hline & & & & $1018,{ }^{\mathrm{k}} 1033^{\mathrm{j}}$ \\
\hline \multirow[t]{2}{*}{$\mathrm{T}_{\mathrm{m}}$ for $\mathrm{SnS}_{2}$} & 66.67 & & & 1138 \\
\hline & & & & $1138,{ }^{\mathrm{j}} 1143^{\mathrm{p}}$ \\
\hline
\end{tabular}

\footnotetext{
${ }^{\mathrm{i}}$ (Sharma and Chang, 1986)

j (Moh, 1969)

k (Karakhanova et al., 1966)

${ }^{1}$ (Orr and Christensen, 1958)

m (Pelabon and Moissan, 1906)

${ }^{\mathrm{n}}$ (Biltz, 1908)

${ }^{\circ}$ (Biltz and Mecklenburg, 1909)

$\mathrm{p}$ (Albers and Schol, 1961)

${ }^{\mathrm{q}}$ (Wiedemeier and Csillag, 1979)

r (Anderson and Ridge, 1943)
} 